\title{
Novos tempos e novos limites nas políticas de vida e saúde
}

Maria Lucia Jacobini

ROSE, N.

A política da própria vida: biomedicina, poder e subjetividade no século XXI. São Paulo: Paulus, 396p., 2013.

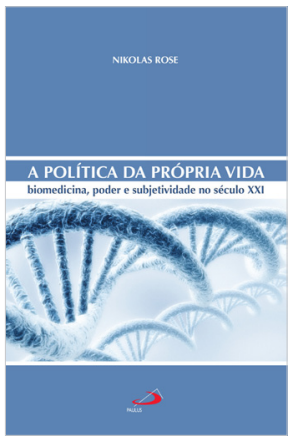

Resumo: Com A política da vida própria, Rose propõe um mapeamento do pensamento sobre as transformações recentes nas ciências da vida. Pensando através dos últimos séculos, o autor discute as mudanças políticas relacionadas às percepções sobre corpo, medicina, doenças, descobertas científicas, indústria farmacêutica e seus efeitos sobre a concepção de sociedade ocidental.

Palavras-chave: biopolítica; biomedicina; inovações médicas.

Abstract: New times and new limits on life and health policies - With The politics of life itself, Rose proposes to map the knowledge related to recent transformations in life sciences. Thinking through the past few centuries, the author discusses the policy changes concerning perceptions about the body, medicine, diseases, scientific discoveries, pharmaceutical industry and its effects on the conception of modern Western society.

Keywords: biopolitics; biomedicine; medical innovations.

Biopolítica, biopoder, biomedicina, bioeconomia, biocapital, bioética e biossocialidade: é com base nesses termos que Rose nos apresenta os avanços e as transformações nas ciências da vida e suas inevitáveis relações - ou implicações - nos campos da política da vida, da não vida, da saúde, da medicina, da biologia e da cidadania. 
Em A política da própria vida, o autor constrói uma cartografia dos avanços das biociências desde o século XVIII até o século XXI, que chama de "século biotécnico". Sua proposta aqui é de expor, com poucos julgamentos, a evolução da biopolítica em termos de saúde, de novas tecnologias médicas, de eugenia e até do fim do Estado como instrumento de dominação e controle de todos os setores da sociedade.

Rose defende que tais transformações simplesmente não mudaram a relação de cada indivíduo com a saúde e com a doença, mas interferiram sobre o que pensamos, o que podemos esperar e sobre o que aspiramos a partir de um novo lugar: o de indivíduos somáticos. Como parte dessa nova categoria, vemo-nos como pacientes ativos, expressamo-nos, julgamos e agimos dentro do escopo, das práticas, dos discursos e da linguagem da biomedicina. Como pertencentes a essa nova época, estamos inevitavelmente ligados às questões da saúde sobre replanejamento da vitalidade, qualidade de vida, direitos de escolha, novos medicamentos, eutanásia e genômica.

Para iniciar seu mapeamento, o autor aborda o que considera ser um novo estilo de pensamento nas políticas da vida no século XXI, com seus efeitos sobre discurso, linguagem e técnicas de experimentação. Pensa a partir de cinco perspectivas: a da molecularização envolve o novo corpo molecular, em que todos seus aspectos são separáveis, manipuláveis e transferíveis e, consequentemente, comercializáveis. A perspectiva da otimização descreve como a biomedicina está engajada no replanejamento biológico da vitalidade, ou seja, está interessada em criar tecnologias que vão além de reestabelecer um "estado normal de saúde" e conseguem controlar os processos vitais do corpo e da mente do presente para já proporcionar um futuro considerado melhor.

Na perspectiva subjetificação, Rose nos fala da criação de um novo cidadão biológico, consumidor ativo de remédios, de ciência ou até de medicinas alternativas capazes de incrementar seu corpo e maximizar sua própria vitalidade. A perspectiva da Expertise, por sua vez, relaciona os novos cidadãos biológicos e suas buscas por saúde com o surgimento de especialistas (profissionais da saúde ou não) que realizam a mediação entre os consumidores de saúde e os campos de conhecimento como doenças, tratamentos e até questões éticas.

Já com a bioeconomia, o autor propõe que uma biologia e uma medicina em nível molecular exigem crescentes investimentos e, portanto, uma íntima ligação com laboratórios e fábricas de tecnologia e medicamentos. É a capitalização das tecnologias da vida que transforma, questionavelmente, a saúde em estatística e as doenças em números.

No capítulo seguinte, Rose toca na questão de como a vida, a morte e a biologia são geográficas e temporalmente variáveis, sujeitas a intervenções políticas. Nesse sentido, apresenta os conceitos de biopoder como poder sobre a vida e os conceitos de biopolítica como o conjunto de práticas de intervenção sobre a vitalidade, a morbidade e a mortalidade humanas que são adequadas, legítimas e eficazes; sempre em um determinado espaço-tempo.

Sempre relembrando a perspectiva de que se pensa hoje a saúde como uma transformação no presente e tendo em vista o futuro maximizado, o terceiro capítulo 
relaciona muitos dos recentes dilemas da saúde; como o desenvolvimento da genética reprodutiva, a prognósticos e especulações. Ressalta que fazemos parte de um contexto voltado para a otimização da vida por meio de técnicas de suscetibilidade (prevenção) e de aprimoramento do corpo e da mente.

As mudanças nos seres humanos e suas percepções de risco são temas do capítulo seguinte. Rose discorre sobre como as evoluções na genética reorganizaram as doenças e patologias e criaram uma obrigação de agir no presente para evitar potenciais problemas, hoje passíveis de antecipação. As pessoas geneticamente arriscadas são agora responsáveis pela sempre presente otimização de suas vidas, prevendo problemas e aprimorando seu corpo molecular. Contudo, embora o corpo possa ser isolado em partes, o indivíduo não se torna isolado. Ao contrário, cria uma rede de conectividade que interliga laços e memórias de família e, segundo o que ressalta o autor, ajuda na composição de identidades múltiplas - práticas biológicas, biomédicas e genéticas.

São esses mesmos indivíduos que compõem uma nova cidadania, típica da era da biomedicina, da biotecnologia, da genômica e a da cidadania biológica. O capítulo seguinte abrange projetos que ligam a concepção de cidadão à biossocialidade e a formas coletivizadoras de família, linhagem, comunidade e população. Além disso, apresenta as transformações da cidadania biológica junto às dimensões do nacional, do local e do transnacional e, consequentemente, ao ressurgimento de questões de raça, eugenia e limpeza social, ligadas a alguns períodos da história ocidental, particularmente ao nazismo.

Já no sexto capítulo, Rose discute especificamente sobre raça e como, na era genômica, há um debate sobre até que ponto as categorias raciais ou étnicas têm algum significado biológico ou são culturais. Para o autor, é preciso pensar a partir da atual biologia molecular genômica, mais aberta, probabilística e não linear, a ponto de identificar uma verdade racial essencial.

Os dois capítulos finais contemplam os desdobramentos da passagem de uma cidadania biológica para uma cidadania neuroquímica e o uso da biologia para explicar o comportamento violento e a criminalidade. No primeiro caso, o indivíduo somático, que se compreende, fala e age sobre si mesmo a partir da biologia, agora tem também começado a estender tal compreensão para seu pensamento, para seus desejos e para suas emoções.

Isso significa que surge um novo padrão relacionado à psiquiatria e à psicofarmacêutica e seu indispensável debate sobre os interesses comerciais da indústria farmacêutica e as reais necessidades e eficácias de seus medicamentos para a mente humana. Quanto ao segundo caso, a criminalidade é abordada por Rose como decorrente de uma nova criminologia biológica, marcada por estratégias pouco compreendidas de controle e mapeamento de criminosos a partir de fatores genéticos e até por sua relação com a eugenia.

Mais especificamente sobre a eugenia, é importante ressaltar que Rose questiona as proposições de Bauman e Agamben de que o desejo eugênico de controlar a constituição biológica da população ainda seria base para as políticas atuais e estaria centrado em 
seu contínuo laço com a eliminação do que seria indesejado ou inadequado por uma figura soberana ${ }^{1}$. Conforme Rose, no século XXI e, principalmente, a partir do lugar do qual fala ao longo de seu livro - os regimes liberais avançados -, não se trataria mais de uma questão de fazer morrer, mas de uma perspectiva totalmente diferente: a de deixar morrer.

Talvez aqui o mapeamento de Rose fique limitado a um determinado cenário, em que realmente não existe um soberano que claramente planeja a exclusão de outro grupo. Contudo, sua própria argumentação evidencia que as reais transformações nas ciências da vida são perceptíveis em apenas alguns poucos contextos. É o que conseguimos observar, por exemplo, em suas discussões sobre como a raça ainda está intrincada às políticas de controle da criminalidade e também sobre como o básico transformador do saneamento básico e da alimentação já há muito é parte de tais sociedades mais ricas. Enquanto isso, outros ao redor do mundo permanecem precisamente excluídos como atores/sujeitos de muitos aspectos pela biotecnologia, biopolítica, biomedicina, bioeconomia, bioética e biossocialidade.

Economista formada pela Unicamp, Jornalista pela PUCCampinas e especialista em Jornalismo Científico pelo Labjor/Unicamp. É Mestre e Doutora pela Comunicação e Semiótica da PUC/SP com bolsa CNPq. Atualmente é jornalista, membro do Grupo de Pesquisa Barroco e Mestiçagem da PUC/SP e docente do Curso de Jornalismo da PUC-Campinas.

mlpjacobini@yahoo.com.br

\section{Referências}

AGAMBEN, G. Homo sacer: o poder soberano e a vida nua. Belo Horizonte: Editora UFMG, 2002.

1 Para Agamben (2002), o soberano tem o poder de decidir quem é matável e sacrificável. 